\title{
Reflexiones en tiempos de crisis
}

Juan Pablo Cruz Quiroga ${ }^{*}$

1. Radiólogo. Pontificia Universidad Católica de Chile. Santiago, Chile.

Estimados miembros de la comunidad radiológica. Habitualmente las editoriales de esta revista apuntan a un tema puntual de nuestro quehacer, exponemos brevemente el problema, luego el estado de situación, para luego intentar dar algunos lineamientos y/o soluciones de ser estas posibles. Para este número, no me fue posible estructurar una editorial de ese modo. El nivel y velocidad de cambios que hemos visto en nuestro país desde el denominado 18-O, seguido luego de la pandemia por el SARS-CoV2 provocando la enfermedad COVID ha alterado el funcionamiento de todos y cada uno de nosotros. Los que pudimos seguir funcionando dentro de cierto rango de normalidad durante los meses previos a marzo, ahora definitivamente tuvimos que cambiar nuestras rutinas y las maneras en que ejercemos nuestra profesión y nuestras funciones. La gran mayoría de los radiólogos ha sido capaz de seguir contribuyendo desde sus hogares u oficinas por medio de informe remoto, y los que no lo tenían bien implementado en sus distintos centros, han tenido que innovar y adaptarse en forma rápida para disminuir las probabilidades de contacto y de contagio de sus médicos. Otros han ideado turnos de grupos aislados entre ellos, para que, si un grupo entra en cuarentena, los otros pueden seguir manteniendo las funciones básicas necesarias del servicio. Merecen una especial distinción y reconocimiento en este momento en particular, los tecnólogos(as) médicos, enfermeras(os) y los/las auxiliares que forman, en nuestra especialidad, esa "primera línea" que es la que está y estará más expuesta a contagios. Los radiólogos(as) ecografistas también han tenido que ajustar en forma significativa su práctica y ajustarse a todas las precauciones necesarias para mantenerse, y mantener a sus contactos/familias, seguros. A todos ellos es el momento de darles nuestro apoyo y agradecimiento, por permitir a los servicios de radiología seguir funcionando, especialmente considerando la importancia que han adquirido los hallazgos radiológicos en esta pandemia.

Quienes participamos activamente en docencia y formación, también hemos visto alterado significativamente nuestra manera de enseñar y de conducir las actividades docentes. En nuestro programa de residentes hemos implementado y ajustado modalidades de enseñanza remota con clases por video conferencia, selección de artículos fundamentales y con material digitalizado disponible para estudio. Si bien jamás podrá reemplazarse la docencia tutorial que proviene del quehacer diario, nos ha permitido seguir formando y reforzando en nuestros residentes el sustento teórico que se necesita para el adecuado aprendizaje de la radiología. Estos cambios han significado una externalidad positiva, ya que, demostrada la factibilidad, ajustes similares pueden aplicarse para reuniones de capítulo, cursos y eventualmente un currículum común de clases para los diversos programas.

Finalmente quisiera destacar que para aquellos que estamos trabajando en salud estamos en un lugar relativamente privilegiado en el escenario actual. Nuestros vecinos, amigos y familiares están asustados, abrumados y confusos por la información proveniente de múltiples canales, cumpliendo distintos grados de aislamiento, muchos de ellos con riesgo de perder su trabajo o no pudiendo trabajar. Nosotros tenemos algo que hacer, algo con que contribuir, actuar y cooperar, y casi seguramente lo seguiremos teniendo después que esto acabe, una especie de paréntesis en nuestras vidas, y eso si es un privilegio. 